\title{
Sudden death in athletes
}

\author{
Vimal Patel and Perry Elliott
}

\begin{abstract}
Sudden cardiac death in an athlete is a rare and heartrending event, often occurring in the absence of warning symptoms. The causes of sudden cardiac death in athletes are age dependent and demonstrate a degree of geographical variation. Pre-participation screening is recommended by both the European Society of Cardiology and the American Heart Association although there is no consensus regarding the utilisation of an electrocardiogram. This article will review the aetiology of sudden cardiac death and will present the evidence for pre-participation screening.
\end{abstract}

KEY WORDS: sudden cardiac death, hypertrophic cardiomyopathy, arrythmogenic cardiomyopathy, channelopathies, coronary artery anomalies, pre-participation screening

\section{Introduction}

Sudden death in a previously healthy young person is always tragic, but the emotional and psychological impact is heightened when the victim is a competitive athlete. Such events are fortunately very rare, but whenever they occur, medical, political and media interests naturally focus on the prevention of similar tragedies. In this short article, we review the common causes of sudden cardiac death in athletes and discuss the evidence for systematic pre-participation screening in this population.

\section{Epidemiology}

Most studies of deaths in athletes are retrospective and subject to reporting bias. The incidence of sudden cardiac death in young competitive athletes varies between 0.5 and 1.21 per 100,000 person-years, ${ }^{1-4}$ but the best prospective data come from the Veneto region of Italy, where the annual incidence of sudden death in athletes was 2.3 per 100,000 person-years from all causes and 2.1 per 100,000 person-years from cardiovascular diseases. ${ }^{5}$ Most series have a male predominance ${ }^{2,5-8}$ and most events occur during or shortly after exercise..$^{2,5,7}$

\section{Aetiology of sudden death in athletes}

The aetiology of sudden cardiac death in athletes is age dependent. Coronary atherosclerosis is the most common cause of sudden death in individuals older than 35 years, whereas inherited and structural heart disease predominate in younger athletes (Table 1). ${ }^{6,9}$ As with the incidence of sudden death, there are geographic differences in reported aetiology. For example, arrhythmogenic right ventricular cardiomyopathy (ARVC) is the most common cause of death in the Veneto region of Italy (Fig 1), ${ }^{5}$ whereas hypertrophic cardiomyopathy is the major cause in many series from the USA., 7 This difference has been suggested to result from regional variations in the prevalence of these diseases, but it is possible that a particular focus on detailed postmortem examination of the right ventricle explains the higher incidence of ARVC in Italy.

\section{Hypertrophic cardiomyopathy}

Hypertrophic cardiomyopathy (HCM), defined as left ventricular hypertrophy in the absence of abnormal loading conditions (valve disease, hypertension and congenital heart defects), ${ }^{10-12}$ occurs in about one in every 500 adults. ${ }^{13}$ Pathologically, the disease is characterised by myocardial hypertrophy, myocyte disarray and myocardial fibrosis, and it is usually inherited as an autosomal dominant trait caused by mutations in genes that encode contractile proteins of the cardiac macromere. ${ }^{11}$ Individuals with HCM are often asymptomatic but can present throughout life with chest pain, symptoms of heart failure, syncope and sudden ventricular arrhythmias. Although HCM is reported in $10-51 \%$ of all sudden or aborted cardiac deaths in young athletes, $2,7,8,14-16$ it is rarely found during pre-participation screening. ${ }^{17}$ Moreover, the incidence of sudden death in non-athletic individuals with the disease is also very low (<1\% per annum). ${ }^{11}$ Explanations for these apparent contradictions include an inability of most individuals with HCM to attain athletic status and a particularly high risk of fatal ventricular arrhythmia in the very small number of individuals who can overcome the physiological limitations imposed by the disease. Little evidence supports either hypothesis, but the high incidence of HCM-related deaths in athletes remains the major justification for the exclusion of individuals with HCM from sporting activities.

\section{Idiopathic left ventricular hypertrophy}

Idiopathic left ventricular hypertrophy (LVH) is defined histologically by the presence of myocyte hypertrophy, sometimes in association with myocardial fibrosis but in the absence of myocyte disarray. In an autopsy study based in the UK, idiopathic $\mathrm{LVH}$ was the most frequently reported cardiac anomaly in young

The Heart Hospital, University College London 
Table 1. Causes of sudden cardiac death in athletes.

\begin{tabular}{|c|c|c|}
\hline Heritability & Structurally abnormal heart & Structurally normal heart \\
\hline Inherited & $\begin{array}{l}\text { - Cardiomyopathies } \\
\text { - Hypertrophic } \\
\text { cardiomyopathy } \\
\text { - Arrythmogenic } \\
\text { cardiomyopathy } \\
\text { - Dilated cardiomyopathy } \\
\text { - Coronary artery anomalies } \\
\text { - Valvular heart disease } \\
\text { - Aortic disease }\end{array}$ & $\begin{array}{l}\text { Channelopathies } \\
\text { - Brugada syndrome } \\
\text { - Long QT syndrome } \\
\text { - Catechol-aminergic } \\
\text { polymorphic ventricular } \\
\text { tachycardia }\end{array}$ \\
\hline Acquired & $\begin{array}{l}\text { - Ischaemic heart disease } \\
\text { - Myocarditis }\end{array}$ & $\begin{array}{l}\text { - } \text { Commotio cordis } \\
\text { - Substance misuse } \\
\text { - Electrolyte imbalance }\end{array}$ \\
\hline
\end{tabular}

athletes experiencing sudden cardiac death. ${ }^{15}$ This phenomenon is poorly understood but may represent physiological adaptation in response to intense training. Other possible explanations include the use of anabolic steroids and hypertension.

\section{Arrhythmogenic right ventricular cardiomyopathy}

Arrhythmogenic right ventricular cardiomyopathy is an inherited heart muscle disease characterised by loss of myocytes, with fatty or fibro-fatty replacement of the right ventricle, ventricular arrhythmias, congestive heart failure and sudden cardiac death. The estimated prevalence of the disease is 1:10001:5000. ${ }^{6,18,19}$ The disease frequently is inherited, with most cases caused by mutations in genes encoding desmosomal proteins. ${ }^{18,20}$ In the early 'concealed' stage of the disease, patients are usually asymptomatic but can be at risk of life-threatening ventricular arrhythmias. ${ }^{21}$ The prevalence of ARVC in young athletes experiencing sudden or aborted cardiac death in the US and France is about $3-4 \% .{ }^{2,7,14}$ In the UK, ARVC is reported as the primary cause of death in $10 \%$ of athletes younger than 35 years and $24 \%$ of those older than 35 years. ${ }^{15}$ In Italy, ARVC accounts for nearly one quarter of all sudden cardiovascular deaths in young athletes. ${ }^{5}$ The relation between exercise and disease progression in ARVC is controversial. Evidence from animal models suggests that endurance training accelerates expression of the clinical phenotype. ${ }^{22}$

\section{Coronary artery abnormalities}

Coronary artery anomalies are present in $1.3-5.6 \%$ of the general population, ${ }^{23,24}$ but may be as common as $24 \%$ in young athletes who experienced sudden cardiac death. ${ }^{16}$ Most sudden cardiac deaths related to coronary abnormalities in athletes are caused by an anomalous origin of the left coronary system from the right coronary sinus. ${ }^{7,16,25}$ The trigger for sudden death is thought to be myocardial ischaemia caused by compression of the anomalous coronary artery as it passes between the aorta and pulmonary artery, the slit-like opening at the ostium and the acute angle at its origin. Other coronary abnormalities identified in athletes who experienced sudden death include coronary hypoplasia, coronary aneurysm, acute angulation at the coronary insertion and intussusception. ${ }^{7}$

\section{Ion channel disease}

Despite extensive pathological and toxicological assessment, a large proportion of sudden cardiac deaths in athletes remain unexplained. ${ }^{2,15}$ This entity of sudden arrhythmic death syndrome (SADS) is often caused by diseases of the cardiomyocyte membrane ion channels (channelopathies) - a heterogenous group of disorders that include long QT syndrome (LQTS), Brugada syndrome and catecholaminergic polymorphic ventricular tachycardia (CPVT). The first presentation of such disorders may be life-threatening cardiac arrhythmia occurring at rest or during exercise. Characteristic electrocardiographic changes in many disorders may be evident only after pharmacological or exercise provocation, and the diagnosis requires a high degree of clinical suspicion, often precipitated by a tragic event in the family (see Ref 26 for a more detailed review of this topic).
Fig 1. Causes of sudden cardiovascular deaths in athletes (aged $<\mathbf{3 5}$ years) in the Veneto region of Italy from 1979 to 1999. Modified from Corrado et al, $2003 .^{5}$

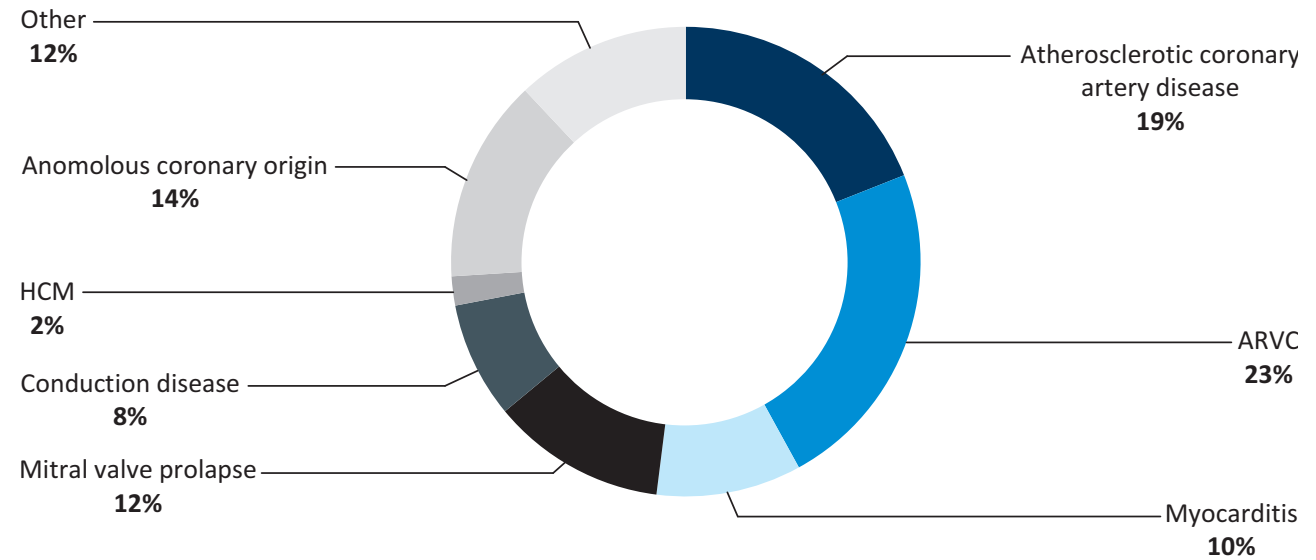




\section{Prevention of sudden death in athletes}

In an attempt to reduce sudden deaths in young athletes, both the European Society of Cardiology (ESC) and American Heart Association (AHA) recommend screening of all individuals who participate in high-level sports. The AHA advises that all athletes should undergo screening solely with a detailed clinical history and physical examination. $^{27}$ In contrast, the ESC recommends that an electrocardiogram (ECG) should be routinely used in screening - a stance endorsed by the International Olympic Committee. ${ }^{28}$ Justification for the inclusion of an ECG in the screening strategy is a prospective study from Italy, where pre-participation screening involving history taking, examination and ECG has been mandatory for 26 years. Data from the Veneto region of Italy show that the incidence of sudden death in young athletes fell from 3.6 per 100,000 personyears to 0.4 per 100,000 person-years during this period. A comparable reduction in the rate of sudden death among unscreened non-athletes was not seen, which led to the conclusion that screening was responsible for the decline in events. ${ }^{6}$ However, these data need to be interpreted cautiously, as the incidence of sudden death in Veneto, prior to implementation of pre-participation screening, was unusually high compared to that in the USA and other European countries (3.6 per 100,000 personyears vs $0.46-1.21$ per 100,000 person-years). ${ }^{1-4}$

The sensitivity and specificity of an ECG-based screening programme is dependent on the criteria used to differentiate physiological adaptation from disease. In a study of 1,005 consecutive athletes, a mildly or distinctly abnormal ECG was 51\% sensitive and $61 \%$ specific for identifying cardiovascular abnormalities, with a positive predictive accuracy of only $7 \%$ and a false-positive rate of $39 \% .{ }^{29}$ In 2005, the ESC published criteria for detecting ECG abnormalities in athletes, ${ }^{28}$ which increased the sensitivity for detecting structural cardiovascular disease from $45 \%$ with history and examination alone, to almost $91 \% .{ }^{30}$ However, there was an associated reduction in specificity (from $94.4 \%$ to $82.7 \%$ ) and an increase in the rate of false-positive results (from 5.5\% to $16.9 \%$ ). In 2010, new guidelines that reclassified some electrocardiographic features (previously described as pathological) as normal variants were proposed (Table 2). ${ }^{31}$ When compared with the original criteria, the 2010 criteria resulted in a reduction in the rate of false-positive results to $10 \%$, without altering sensitivity. ${ }^{32}$ Although the latest guidance has improved the performance of ECGs for screening in adults, the applicability of ECGs in younger age groups and different ethnic groups is unknown. ${ }^{33}$ This screening strategy will also miss conditions in which ECG changes can be transient (for example, Brugada syndrome and CPVT) or absent (as in anomalous coronary arteries).

\section{Cost effectiveness}

As the incidence of sudden death among athletes is low, the costs of implementing a screening programme are substantial. Estimates suggest that the inclusion of an ECG would increase the cost of pre-participation screening in the US by $\$ 500$ million to an annual total of $\$ 2$ billion, with a cost of $\$ 3.4$ million per theoretical life saved. ${ }^{27}$ Other studies have shown that screening with ECG costs about \$44,000-76,100 per year of life saved and is more cost effective than screening history and examination alone. ${ }^{34,35}$

Irrespective of the financial arguments about screening, the fact that a substantial proportion of sudden deaths in young individuals are attributable to genetic cardiovascular diseases means that their surviving relatives are also at risk. The firstdegree relatives of young victims of sudden death therefore should be counselled on their risk of a similar event and offered systematic cardiac evaluation in expert centres. This systematic approach has a high yield in terms of identifying other affected family members and may prevent further catastrophic events in the same family.

\section{Conclusions}

Sudden cardiac death in athletes is a tragic and potentially preventable event. The aetiology of sudden death is age dependent and frequently relates to inherited cardiovascular disease in the young. Pre-participation screening may help to reduce the incidence of sudden death, although equal focus should be given to evaluation of the families of victims of sudden death.

\section{References}

1 Maron BJ, Gohman TE, Aeppli D. Prevalence of sudden cardiac death during competitive sports activities in Minnesota high school athletes. J Am Coll Cardiol 1998;32:1881-4.

2 Maron BJ, Doerer JJ, Haas TS et al. Sudden deaths in young competitive athletes: analysis of 1866 deaths in the United States, 1980-2006. Circulation 2009;119:1085-92. 
3 Holst AG, Winkel BG, Theilade J et al. Incidence and etiology of sports-related sudden cardiac death in Denmark - implications for preparticipation screening. Heart Rhythm 2010;7:1365-71.

4 Maron BJ, Haas TS, Doerer JJ et al. Comparison of U.S. and Italian experiences with sudden cardiac deaths in young competitive athletes and implications for preparticipation screening strategies. Am J Cardiol 2009; 104:276-80.

5 Corrado D, Basso C, Rizzoli G et al. Does sports activity enhance the risk of sudden death in adolescents and young adults? J Am Coll Cardiol 2003;42:1959-63.

6 Corrado D, Basso C, Pavei A et al. Trends in sudden cardiovascular death in young competitive athletes after implementation of a preparticipation screening program. JAMA 2006;296:1593-601.

7 Maron BJ, Shirani J, Poliac LC et al. Sudden death in young competitive athletes. Clinical, demographic, and pathological profiles. JAMA 1996;276:199-204.

8 Van Camp SP, Bloor CM, Mueller FO et al. Nontraumatic sports death in high school and college athletes. Med Sci Sports Exerc 1995;27:641-7.

9 Maron BJ. Sudden death in young athletes. N Engl J Med 2003;349:1064-75

10 Elliott P, Andersson B, Arbustini E et al. Classification of the cardiomyopathies: a position statement from the European Society of Cardiology Working Group on Myocardial and Pericardial Diseases. Eur Heart J 2008:29:270-6.

11 Elliott P, McKenna WJ. Hypertrophic cardiomyopathy. Lancet 2004;363:1881-91.

12 Maron BJ, McKenna WJ, Danielson GK et al. American College of Cardiology/European Society of Cardiology clinical expert consensus document on hypertrophic cardiomyopathy. A report of the American College of Cardiology Foundation Task Force on Clinical Expert Consensus Documents and the European Society of Cardiology Committee for Practice Guidelines. J Am Coll Cardiol 2003;42: 1687-713.

13 Maron BJ, Peterson EE, Maron MS, Peterson JE. Prevalence of hypertrophic cardiomyopathy in an outpatient population referred for echocardiographic study. Am J Cardiol 1994;73:577-80.

14 Marijon E, Tafflet M, Celermajer DS et al. Sports-related sudden death in the general population. Circulation 2011;124:672-81.

15 de Noronha SV, Sharma S, Papadakis M et al. Aetiology of sudden cardiac death in athletes in the United Kingdom: a pathological study. Heart 2009;95:1409-14.

16 Bille K, Figueiras D, Schamasch P et al. Sudden cardiac death in athletes: the Lausanne recommendations. Eur J Cardiovasc Prev Rehabil 2006;13:859-75.

17 Basavarajaiah S, Wilson M, Whyte G et al. Prevalence of hypertrophic cardiomyopathy in highly trained athletes: relevance to pre-participation screening. J Am Coll Cardiol 2008;51:1033-9.

18 Basso C, Corrado D, Marcus FI et al. Arrhythmogenic right ventricular cardiomyopathy. Lancet 2009;373:1289-300.

19 Peters S, Trummel M, Meyners W. Prevalence of right ventricular dysplasia-cardiomyopathy in a non-referral hospital. Int J Cardiol 2004;97:499-501.

20 Awad MM, Calkins H, Judge DP. Mechanisms of disease: molecular genetics of arrhythmogenic right ventricular dysplasia/cardiomyopathy. Nat Clin Pract Cardiovasc Med 2008;5:258-67.

21 Thiene G, Nava A, Corrado D et al. Right ventricular cardiomyopathy and sudden death in young people. N Engl J Med 1988;318:129-33.

22 Kirchhof P, Fabritz L, Zwiener M et al. Age- and training-dependent development of arrhythmogenic right ventricular cardiomyopathy in heterozygous plakoglobin-deficient mice. Circulation 2006;114:1799_ 806.

23 Angelini P, Vilason S, Chan AV, Diez JG. Coronary artery anomolies: a comprehensive approach. Philadephia: Lippincott Williams \& Wilkins, 1999.

24 Yamanaka O, Hobbs RE. Coronary artery anomalies in 126,595 patients undergoing coronary arteriography. Cathet Cardiovasc Diagn 1990;21:28-40.

25 Basso C, Maron BJ, Corrado D, Thiene G. Clinical profile of congenital coronary artery anomalies with origin from the wrong aortic sinus leading to sudden death in young competitive athletes. J Am Coll Cardiol 2000;35:1493-501.

26 Bastiaenen R, Behr ER. Sudden death and ion channel disease: pathophysiology and implications for management. Heart 2011;97:1365-72.

27 Maron BJ, Thompson PD, Ackerman MJ et al. Recommendations and considerations related to preparticipation screening for cardiovascular abnormalities in competitive athletes: 2007 update: a scientific statement from the American Heart Association Council on Nutrition, Physical Activity, and Metabolism: endorsed by the American College of Cardiology Foundation. Circulation 2007;115:1643-55.

28 Corrado D, Pelliccia A, Bjornstad HH et al. Cardiovascular pre-participation screening of young competitive athletes for prevention of sudden death: proposal for a common European protocol. Consensus statement of the Study Group of Sport Cardiology of the Working Group of Cardiac Rehabilitation and Exercise Physiology and the Working Group of Myocardial and Pericardial Diseases of the European Society of Cardiology. Eur Heart J 2005;26:516-24.

29 Pelliccia A, Maron BJ, Culasso F et al. Clinical significance of abnormal electrocardiographic patterns in trained athletes. Circulation 2000;102:278-84.

30 Baggish AL, Hutter AM, Wang F et al. Cardiovascular screening in college athletes with and without electrocardiography: a cross-sectional study. Ann Intern Med 2010;152:269-75.

31 Corrado D, Pelliccia A, Heidbuchel $\mathrm{H}$ et al. Recommendations for interpretation of 12-lead electrocardiogram in the athlete. Eur Heart $J$ 2010;31:243-59.

32 Weiner RB, Hutter AM, Wang F et al. Performance of the 2010 European Society of Cardiology criteria for ECG interpretation in athletes. Heart 2011;97:1573-7.

33 Sharma S, Ghani S, Papadakis M. ESC criteria for ECG interpretation in athletes: better but not perfect. Heart 2011;97:1540-1.

34 Wheeler MT, Heidenreich PA, Froelicher VF et al. Cost-effectiveness of preparticipation screening for prevention of sudden cardiac death in young athletes. Ann Intern Med 2010;152:276-86.

35 Fuller CM. Cost effectiveness analysis of screening of high school athletes for risk of sudden cardiac death. Med Sci Sports Exerc 2000;32:887-90.

Address for correspondence: Dr Perry Elliott,

The Heart Hospital, 16-18 Westmoreland Street, London W1G 8PH.

Email: perry.elliott@ucl.ac.uk 